\title{
Secretory leukoprotease inhibitor inhibits cell growth through apoptotic pathway on ovarian cancer
}

\author{
KEIICHIRO NAKAMURA ${ }^{1}$, NORIO TAKAMOTO ${ }^{1}$, ATSUSHI HONGO ${ }^{1}$, JUNICHI KODAMA ${ }^{1}$, \\ FERNANDO ABRZUA ${ }^{2}$, YASUTOMO NASU ${ }^{2}$, HIROMI KUMON ${ }^{2}$ and YUJI HIRAMATSU ${ }^{1}$ \\ Departments of ${ }^{1}$ Obstetrics and Gynecology, and ${ }^{2}$ Urology, Okayama University Graduate \\ School of Medical, Dentistry and Pharmaceutical Sciences, Okayama 700-8558, Japan
}

Received October 17, 2007; Accepted February 1, 2008

\begin{abstract}
In light of the poor prognosis for ovarian cancer, research continues for innovative and efficacious treatment modalities. It is now widely accepted that new approaches for the treatment of ovarian cancers are pivotal in further improving prognosis of this disease. Secretory leukoprotease inhibitor (SLPI) is an 11.7-kDa non-glycosylated, serine protease inhibitor that has a broad inhibitory spectrum against serine protease. SLPI showed potential therapeutic inhibitory effects mediated by tumor necrosis factor (TNF)related apoptosis-inducing ligand (TRAIL), TNF- $\alpha$, death receptor (DR)-4, DR-5 and TNF receptor (TNFR)-I expression which lead to an activation of apoptosis pathway through Caspase-2, Caspase-8 and Caspase-9. We examined whether levels of SLPI protein expression correlated with clinicopathological characteristics in 58 ovarian cancer samples, and investigated the role of SLPI and its biological functions. SLPI expression showed a significant correlation between low expression of SLPI and amount of ascites $(p=0.021)$, lymph node metastasis $(\mathrm{p}=0.011)$. We propose that SLPI could be considered a therapeutic target for the treatment of ovarian cancer.
\end{abstract}

Correspondence to: Dr Keiichiro Nakamura, Department of Obstetrics and Gynecology, Okayama University Graduate School of Medical, Dentistry and Pharmaceutical Sciences, 2-5-1 Shikata-cho, Okayama 700-8558, Japan

E-mail: k-nakamu@cc.okayama-u.ac.jp

Abbreviations: SLPI, secretory leukoprotease inhibitor; TNF- $\alpha$, tumor necrosis factor- $\alpha$; TRAIL, tumor necrosis factor related apoptosis-inducing ligand; tumor necrosis factor (TNF)-related apoptosis-inducing ligand; DR, death receptor; TNFR-I, tumor necrosis factor receptor-I; DMEM, Dulbecco's modified Eagle's medium; FBS, fetal bovine serum; RT-PCR, reverse transcription PCR; PBS, phosphate-buffered saline

Key words: secretory leukoprotease inhibitor, ovarian cancer, apoptotic pathway, caspase

\section{Introduction}

Despite its pervasive impact, the etiology of ovarian cancer and the factors that promote its progression are not yet well understood. Although chemotherapy remains a major treatment modality for human ovarian cancer, chemo-resistance is a clinical problem that severely limits the success of the treatment. It is now widely accepted that new approaches for the treatment of ovarian cancers are pivotal in further improving prognosis of this disease.

SLPI, an 11.7-kDa non-glycosylated, serine protease inhibitor with 107 amino acids, that is produced by different cell types including breast, lung, endometrium, ovary, salivary glands and various host inflammatory and immune cells such as macrophages, neutrophils and B lymphocytes (1-3). It was initially identified as a serine proteinase inhibitor against neutrophil elastase, cathepsin G, trypsin and chymotrypsin (4). SLPI suppressed bacterial growth and inhibited HIV-1 infection of macrophages at physiological concentrations $(5,6)$. Also, SLPI has been shown to play an important role in regulating inflammatory responses by reducing inflammatory gene expression and diminishing inflammatory cell accumulation after hepatic, lung injuries $(7,8)$. Moreover, mice deficient for SLPI showed impaired cutaneous wound healing with increased inflammation and $\mathrm{TNF}-\alpha$ activity, as well as increased elastase activity and reduced extracelluar matrix (9). Furthermore, a single injection of an adenovirus vector carrying SLPI showed a dramatic anti-tumor effect on a xenotransplanted human lung and ovarian cancer $(10,11)$. However, little is known about its mechanisms of action.

Several members of the TNF family have been shown to induce apoptosis in susceptible cells by activation of the caspase pathway (12-14). TNF-related apoptosis-inducing ligand (TRAIL) is considered a promising anticancer agent due to its ability to induce apoptosis in a variety of tumor cell types while having only negligible effects on normal cells $(15,16)$. Sensitivity to TRAIL-induced apoptosis is a key factor influencing the efficacy of TRAIL treatment through interaction on death domain-containing receptors of death receptor (DR)-4 and DR-5 (17).

The purpose of the current study was to examine whether SLPI expression correlated with clinicopathological characteristics in patients suffering from ovarian cancer, and 
biological functions of SLPI on ovarian cancer. Our data clearly implicate of that SLPI as a potential target for gene therapy of ovarian cancer.

\section{Materials and methods}

Cell culture, media and generation of transfectants. OVCAR-3 (ATCC No. HTB-161), SKOV-3 (ATCC No. HTB-77) cancer cell lines were derived from human ovarian carcinomas. These ovarian cancer cells were maintained in Dulbecco's modified Eagle's medium (DMEM) (Life Technologies, Grand Island, NY), supplemented with $10 \%$ fetal bovine serum (FBS). Cells were maintained at $37^{\circ} \mathrm{C}$ in an atmosphere with $5 \% \mathrm{CO}_{2}$ in air. A full-length SLPI cDNA expression vector was transfected into both ovarian cancer cell lines using TransFast transfection reagent (Promega, Madison, WI). Mock transfected cells served as a control.

Matrigel invasion assay. To investigate differences in invasive ability between cells expressing SLPI, we used BD BioCoat Matrigel Invasion Chamber (BD Bioscience, Bedford, MA). After 12, 24, 36 and $48 \mathrm{~h}$ of incubation, membranes were removed from the insert and mounted on slides, then the invading cells were counted under the microscope. Matrigel assays were performed in triplicate.

Real-time quantitative PCR and reverse transcription PCR (RT-PCR) assay. Real-time quantitative RT-PCR was performed using a rapid Lightcycler thermal cycler instrument (Roche Diagnostics, Light Cycler, Mannheim, Germany) under conditions recommended by the manufacturer. The real-time PCR used the primers for SLPI, TRAIL, TNF- $\alpha$ and Fas L, as described previously $(18,19)$. Standard curves for the calculation of the number of transcripts were elaborated using plasmids containing the respective amplified fragment as an insert, and were corrected by using GAPDH as the reference gene. In RT-PCR, we used primers, DR-4, DR-5, TNFR-1 as described previously $(20,21)$. The number of PCR cycles resulting in PCR products in the linear logarithmic phase of amplification curve was determined. PCR samples were electrophoresed on $2 \%$ agar gel and visualized by ethidium bromide.

Western blot analysis. Cell lysates were collected and estimated using a Protein Assay system (Bio-Rad, Hercules, CA) according to the manufacturer's protocols. Proteins from each cell line were subjected to SDS-PAGE, and were transferred onto a nitrocellulose membrane. Polyclonal and monoclonal antibodies used for immunoblotting were as follows: SLPI (Santa Cruz Biotechnology, Santa Cruz, CA), Caspase-2, Caspase-8, Caspase-9 and $\beta$-actin (Sigma Chemical, St. Louis, MO). Working dilution of all of these primary antibobies was 1:1000. Membranes were then incubated with appropriate secondary antibodies. Expressions of antigen-antibody complexes were detected with an enhanced chemiluminesence kit (Amershan Biosciences, Piscataway, NJ).

Cell growth in monolayers and anchorage-independent cell growth in soft-agar. Cell growth in monolayers, cells were plated at a density of $3 \times 10^{4}$ cells/well in 6 -well plates containing DMEM with supplemented with 10\% FBS. Cell proliferations were assessed by counting the cell numbers in triplicate after 1, 3, 5 and 7 days using hemocytometer.

On anchorage-independent cell growth in soft-agar, a cell suspension ( $1 \times 10^{4}$ cells/well) in $1 \mathrm{ml} 0.2 \%$ Noble agar DMEM with $10 \%$ FBS was overlaid onto a $35-\mathrm{mm}$ dish containing a $0.5 \%$-agar base. Colonies $>0.2 \mathrm{~mm}$ in diameter were counted on 28th day after culture. Soft agar assays were performed in triplicate.

Cell cycle analysis. Cells were trypsinized, washed twice with phosphate-buffered saline (PBS), incubated with trypsin for $10 \mathrm{~min}$ at room temperature, incubated with trypsin inhibitor and RNase buffer for $10 \mathrm{~min}$ at room temperature, and stained with $200 \mu 1$ propidium iodide staining solution for $10 \mathrm{~min}$ in the dark, at room temperature (Becton-Dickinson, San Jose, CA). Finally, cells were analyzed with the FACS cytometer (Calibur ${ }^{\mathrm{TM}}$, Becton-Dickinson). The cell cycle phase distribution was determined using CellQuest software (Becton-Dickinson).

MTS assay and FITC-conjugated Annexin V. In order to evaluate the cell proliferation effects of SLPI, MTS assay (Promega) was performed. Cells were treated either with or without transient transfection with SLPI treatment for 12, 24, 36 and $48 \mathrm{~h}$ and then MTS was added for $1 \mathrm{~h}$. The absorbance was read at a wavelength of $490 \mathrm{~nm}$ using an ELISA plate-reader (Bio-Rad Systems). Moreover, apoptosis was measured by staining with FITC-conjugated annexin V using a MEBCYTO Apoptosis Kit (MBL, Nagoya, Japan) according to the manufacturer's recommendations with flow cytometric analysis.

Patients and tissues. The patient population for this study consisted of 58 patients presenting with malignant epithelial ovarian tumor (Department of Obstetrics and Gynecology of Okayama University Medical School, Okayama, Japan). All specimens were obtained at the time of surgery from the primary lesion. The histological cell types of tumors were assigned according to the WHO classification: 35 were classified as serous cell type, 11 as endometrioid cell type, 1 as mucinous cell type and 11 as clear cell type. Surgical staging was reviewed based on the International Federation of Obstetrics and Gynecology (FIGO) staging system: 17 were stage I, 6 were stage II, 30 were stage III and 5 were stage IV. Tumor specimens were fixed in $10 \%$ neural-buffered formalin immediately after excision, dehydrated through graded series of ethanol and xylene, embedded in paraffin.

Immunohistochemical analysis and staining evaluation. Formalin-fixed, paraffin-embedded sections, at $4 \mu \mathrm{m}$ thick, were deparaffinized with xylene and rehydrated in ethanol. Endogenous peroxidase activity was quenched by methanol containing $0.3 \%$ hydrogen peroxidase for $15 \mathrm{~min}$. Then, sections were incubated at room temperature with a primary antibody for SLPI followed by staining using a streptavidinbiotin-peroxidase kit (Nichirei, Tokyo, Japan). The sections were counterstained with hematoxylin. The level of SLPI staining in epithelial cells was classified into three groups by scoring the percentage of positive cells: strong (2), $>50 \%$ of 
(A)

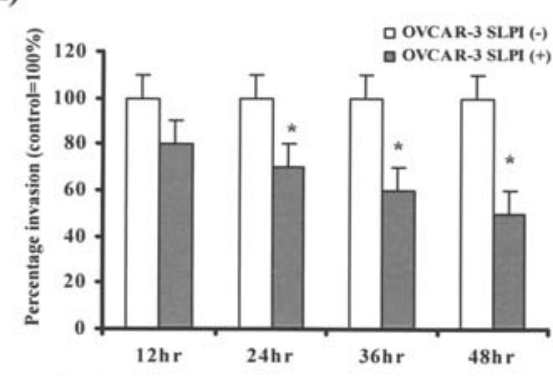

(B)

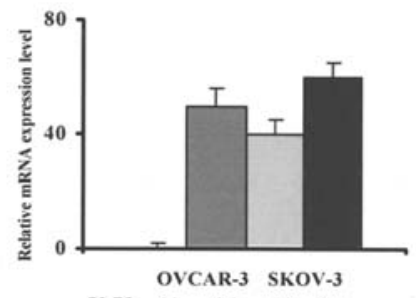

(D)

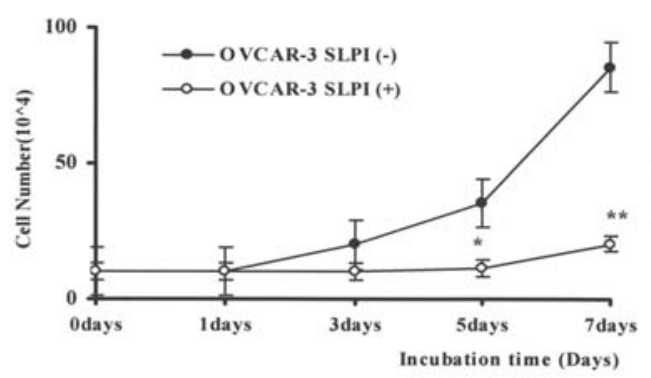

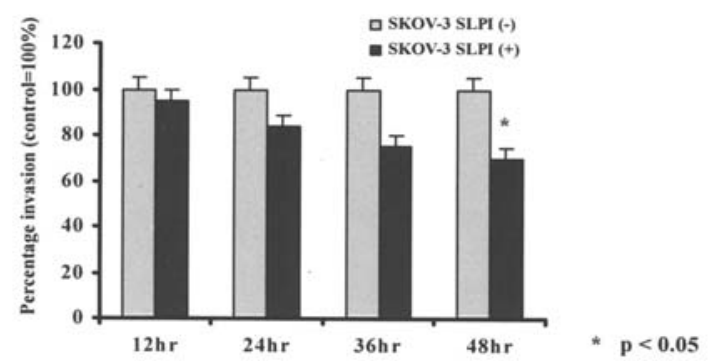

(C)

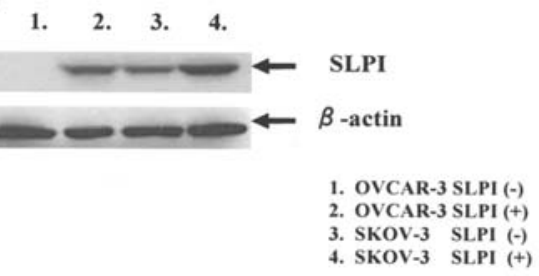

Figure 1. Evaluation of transient transfection of SLPI for 48-h treatment into OVCAR-3 and SKOV-3 ovarian cancer cells. (A) Matrigel invasion assay by SLPI into OVCAR-3 and SKOV-3 ovarian cancer cells. Cells were plated at a density of 5x10 4 cells/well in 24 -well plates, and were incubated for $12,24,36$ and $48 \mathrm{~h}$ in DMEM supplemented with 5\% FBS. Following incubation, membranes were removed from the insert and mounted on slides, and the invading cells were counted under the microscope. Matrigel assays were performed in triplicate. (B) Analyzed for SLPI expression using real-time quantitative PCR. GAPDH was used as loading control. (C) Total cell lysates were prepared from transient transfection of SLPI for 48-h treatment on OVCAR-3 and SKOV-3 ovarian cancer cells; and cells were analyzed for SLPI expression by Western blotting. B-actin antibody was used as loading control in the same blot. (D) Monolayer growth of SLPI treatment in OVCAR-3 and SKOV-3 ovarian cancer cells. Cells were plated at a density of $2.5 \times 10^{4}$ cells/well in 6-well plates, and were incubated for 7 days in DMEM supplemented with 10\% FBS. Numbers of cells were determined after an additional 1,3 , 5 and 7 days. Numbers represent data from triplicate experiments.

cells stained; moderate (1), 10-50\% of cells stained; and weak $(0),<10 \%$ of cells stained. Microscopic analyses were independently conducted by two independent examiners with no prior knowledge of the clinical data. Final decisions in controversial cases were made using a conference microscope.

Statistical analysis. Statistical analyses were performed using the Mann-Whitney U test for comparison with the control and one-factor ANOVA followed by Fisher's protected least significance difference test for all pairwise comparisons. The Analyses were performed with the software package StatView version 5.0 (Abacus Concepts, Berkeley, CA). Differences were considered significant at $\mathrm{p}<0.05$.

\section{Results}

Matrigel invasion of transient transfection of SLPI into OVCAR-3 and SKOV-3 cell lines. We assessed motility and invasiveness of cells overexpressing SLPI by using a BioCoat Matrigel Invasion Chamber. The percentage of cells reaching the bottom of the filter was decreased to 89.5 and
$95.2 \%$ of control at $12 \mathrm{~h}, 70.9$ and $84.1 \%$ at $24 \mathrm{~h}, 59.8$ and $77.0 \%$ at $36 \mathrm{~h}$, and 47.8 and $69.7 \%$ at $48 \mathrm{~h}$ after transient transfection of SLPI into OVCAR-3 and SKOV-3 cell lines, respecting. Since both cell lines showed maximum inhibitory effect at $48 \mathrm{~h}$ post-transfection, $48 \mathrm{~h}$ transient transfection of SLPI was chosen for further experiments (Fig. 1A).

Expression of SLPI increased by transient transfection of SLPI into OVCAR-3 and SKOV-3 cell lines. Level of mRNA and protein of SLPI were determined using real-time PCR analysis and Western blotting. To examine functional role of SLPI, transient cell lines which overexpress SLPI were generated as described in Materials and methods. Both SLPI mRNA and protein were undetectable in OVCAR-3 and readily detected in SKOV-3 cell lines, and transient transfection of SLPI caused significant increase of mRNA and protein levels in both cell lines (Fig. 1B and C).

Inhibition of cell growth in a monolayer of transient transfection of SLPI into OVCAR-3 and SKOV-3 cell lines. Effects of SLPI expression on cell proliferation were analyzed using 
(A)

(B)
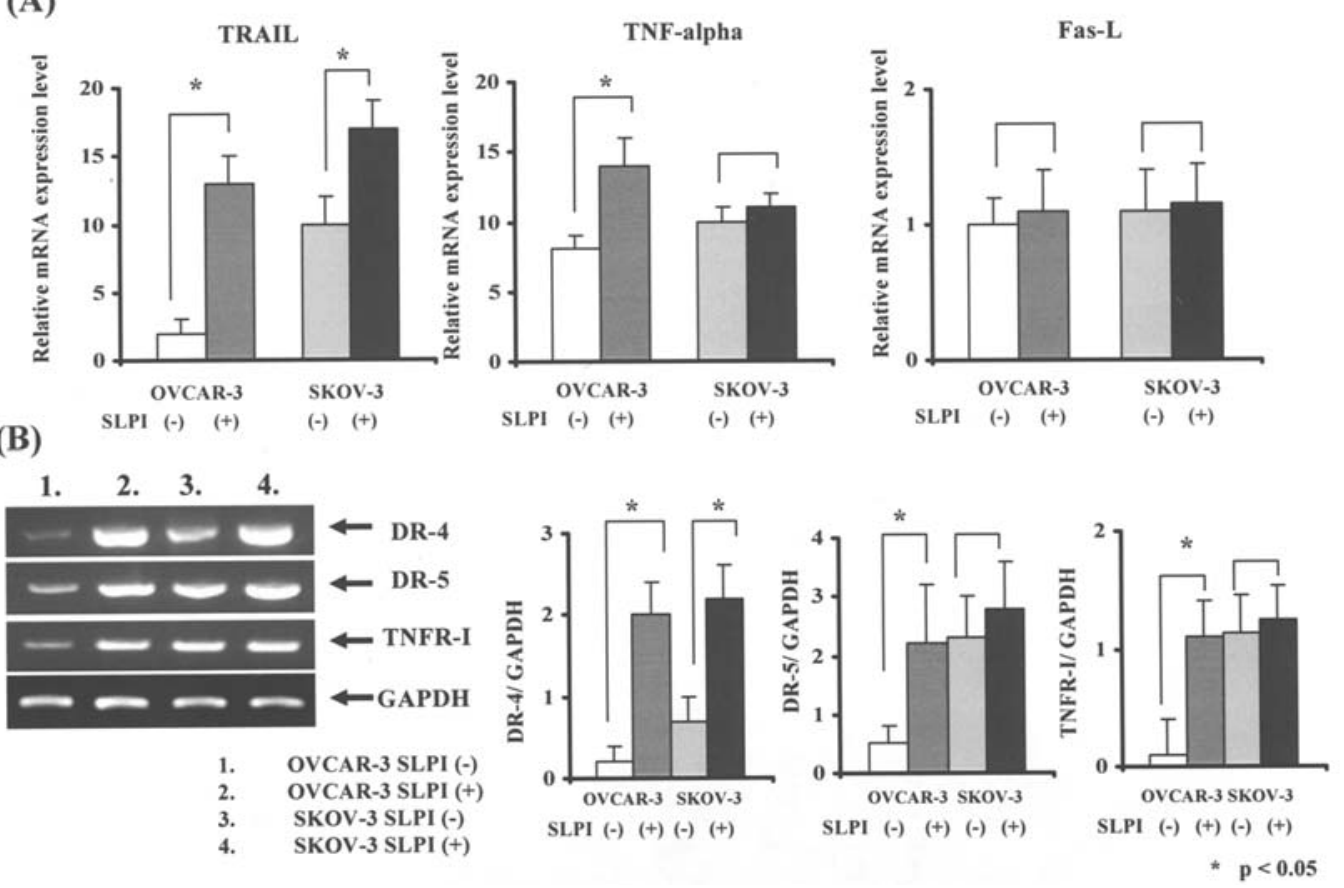

Figure 2. Effects on TNF family pathway by SLPI for 48-h treatment into OVCAR-3 and SKOV-3 ovarian cancer cells. (A) Transient transfection of SLPI into OVCAR-3 and SKOV-3 ovarian cancer cells were analyzed for TRAIL, TNF- $\alpha$ and Fas-L expression using real-time quantitative PCR. GAPDH was used as loading control. The results represent the mean \pm SD of triplicate independent experiments $\left({ }^{*} \mathrm{p}<0.05\right)$. (B) Transient transfection of SLPI into OVCAR-3 and SKOV-3 ovarian cancer cells were analyzed for DR-4, DR-5 and TNFR-I expression using quantitative PCR. GAPDH was used as loading control. The results represent the mean $\pm \mathrm{SD}$ of triplicate independent experiments $\left({ }^{*} \mathrm{p}<0.05\right)$.

transient transfection of SLPI into OVCAR-3 and SKOV-3 cell lines. Consistent with above observation, we found a significant inhibitory effect of SLPI on cell growth in monolayer cultures. Furthermore, the transient transfection of SLPI into OVCAR-3 cell was significantly inhibited more than transient transfection of SLPI into SKOV-3 cell (Fig. 1D).

Expression of TNF family increased by transient transfection of SLPI into OVCAR-3 and SKOV-3 cell lines. Depending on cellular contexts, TNF activation can cause cell cycle arrest or apoptosis, and both responses contribute to tumor suppression. They are known to act as regulators in programmed cell death, embryonic development and cell differentiation (12-14). Since is has been reported that SLPI had anti-tumor effects $(10,11)$ and affects TNF- $\alpha$ activity (9). We examined expression of TNF family members, and their receptors in ovarian cancer cell lines. Real-time PCR analysis revealed that significant increase of TRAIL mRNA in both OVCAR-3 and SKOV-3. Additionally, TNF- $\alpha$ mRNA was significantly increased in OVCAR-3 cells by SLPI (Fig. 2A). The quantitative PCR analysis revealed that expression of DR-4, DR-5, TNFR-1 were significantly increased by SLPI on OVCAR-3. Similarly, expression of DR-4 was increased by SLPI on SKOV-3. However, no significant change in DR-5 and TNFR-1 were observed on SKOV-3 (Fig. 2B).

Accumulation of transient transfection of SLPI into OVCAR-3

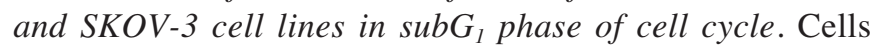
usually respond to genotoxic stress by activating cell cycle checkpoints, and by blocking further progression into the cell cycle, allowing the cells to repair DNA damage. Cell cycle arrest was mainly observed at subG $_{1}$ phase by SLPI on both
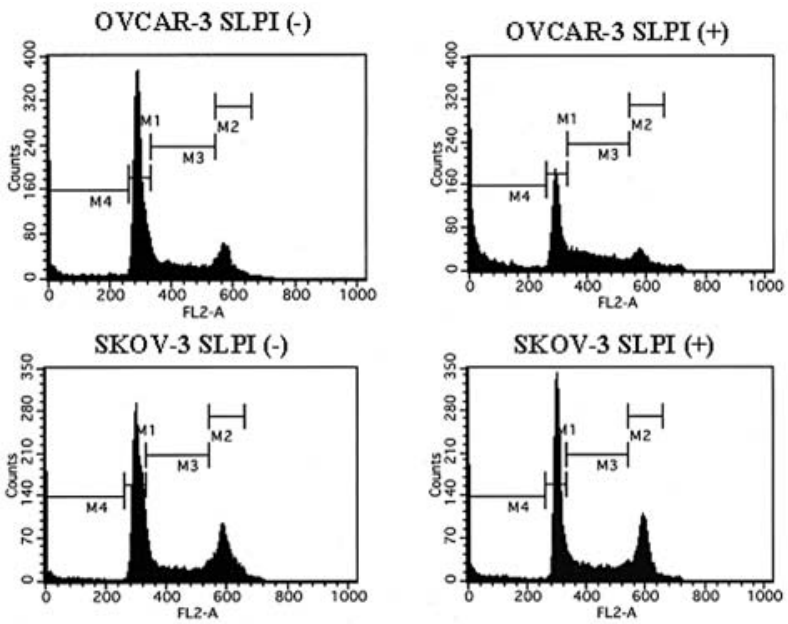

Figure 3. Transient transfection of SLPI treatment for 48-h treatment into OVCAR-3 and SKOV-3 ovarian cancer cells were analyzed by a cell cycle assay. Representative cell cycle profiles, measured by propidium iodide (PI) staining with percentages of cells in the $\mathrm{subG}_{1}, \mathrm{G}_{0}-\mathrm{G}_{1}, \mathrm{~S}, \mathrm{G}_{2}-\mathrm{M}$ phases, are shown.

OVCAR-3 and SKOV-3 cancer cells. The effect of SLPI on subG $_{1}$ arrest was more prominent in OVCAR-3 cells than in SKOV-3 cell (Fig. 3 and Table I). These data indicate that SLPI might act to cause cell cycle arrest at the $\mathrm{subG}_{1}$ phase, supporting the idea that SLPI is inhibitory to cell growth and a significant proportion of cells were found to be apoptotic.

The transient transfected of SLPI into OVCAR-3 and SKOV-3 cell line increased the apoptosis progress. We used MTS, and 
Table I. Cell stained with PI were subjected to flow cytometric analysis for cell distributions at each phase of cell cycle either with or without transient transfection of SLPI treatment.

\begin{tabular}{lrcrc}
\hline Cell & $\begin{array}{c}\mathrm{SubG}_{1} \\
(\%)\end{array}$ & $\begin{array}{c}\mathrm{G}_{0}-\mathrm{G}_{1} \\
(\%)\end{array}$ & $\begin{array}{c}\mathrm{G}_{2}-\mathrm{M} \\
(\%)\end{array}$ & $\begin{array}{c}\mathrm{S} \\
(\%)\end{array}$ \\
\hline OVCAR-3 & & & & \\
$\quad$ SLPI (-) & 10.04 & 54.48 & 13.64 & 21.84 \\
SLPI (+) & 35.7 & 29.94 & 9.47 & 24.89 \\
SKOV-3 & & & & \\
SLPI (-) & 5.77 & 47.19 & 25.12 & 21.92 \\
SLPI (+) & 12.33 & 39.58 & 24.04 & 24.05 \\
\hline
\end{tabular}

Table II. Colony formation on soft agar of SLPI transfectants transfected into OVCAR-3 and SKOV-3 ovarian cancer cells.

\begin{tabular}{lccc}
\hline Cells & SLPI & $\begin{array}{c}\text { Average no. of } \\
(\text { mean } \pm \text { SD) }\end{array}$ & $\begin{array}{c}\text { Inhibitory } \\
\text { effect (\%) }\end{array}$ \\
\hline OVCAR-3 & SLPI (-) & $8.8 \pm 1.8$ & 0 \\
& SLPI (+) & $1.0 \pm 0.2$ & $88.6^{\mathrm{b}}$ \\
SKOV-3 & SLPI (-) & $61.5 \pm 10.2$ & 0 \\
& SLPI (+) & $29.3 \pm 2.6$ & $52.3^{\mathrm{c}}$ \\
\hline
\end{tabular}

${ }^{a}$ Numbers represent data from triplicate experiments. ${ }^{b} \mathrm{p}<0.01$; ${ }^{\mathrm{c}} \mathrm{p}<0.05$.
FITC-conjugated Annexin V assays to examine apoptosis caused by SLPI on OVCAR-3 and SKOV-3 ovarian cancer cells. Transient transfection of SLPI caused reduced cell growth in MTS assay on OVCAR-3 and SKOV-3 cells (Fig. 4A). Also, SLPI induced apoptosis on OVCAR-3 and SKOV-3 cancer cells, which was assessed by annexin V-FITC assay, as shown in Fig. 4B. Depending on cellular contexts,
Caspase activation can cause cell cycle arrest or apoptosis, and both responses contribute to tumor suppression. We analyzed Caspase-2, Caspase- 8 and Caspase- 9 protein expression transient transfection with SLPI treatment on OVCAR-3, and SKOV-3 cancer cell lines. As shown in Fig. 4C, Western blot analysis revealed that expression of Caspase-2, Caspase- 8 and Caspase- 9 were significantly

(A)
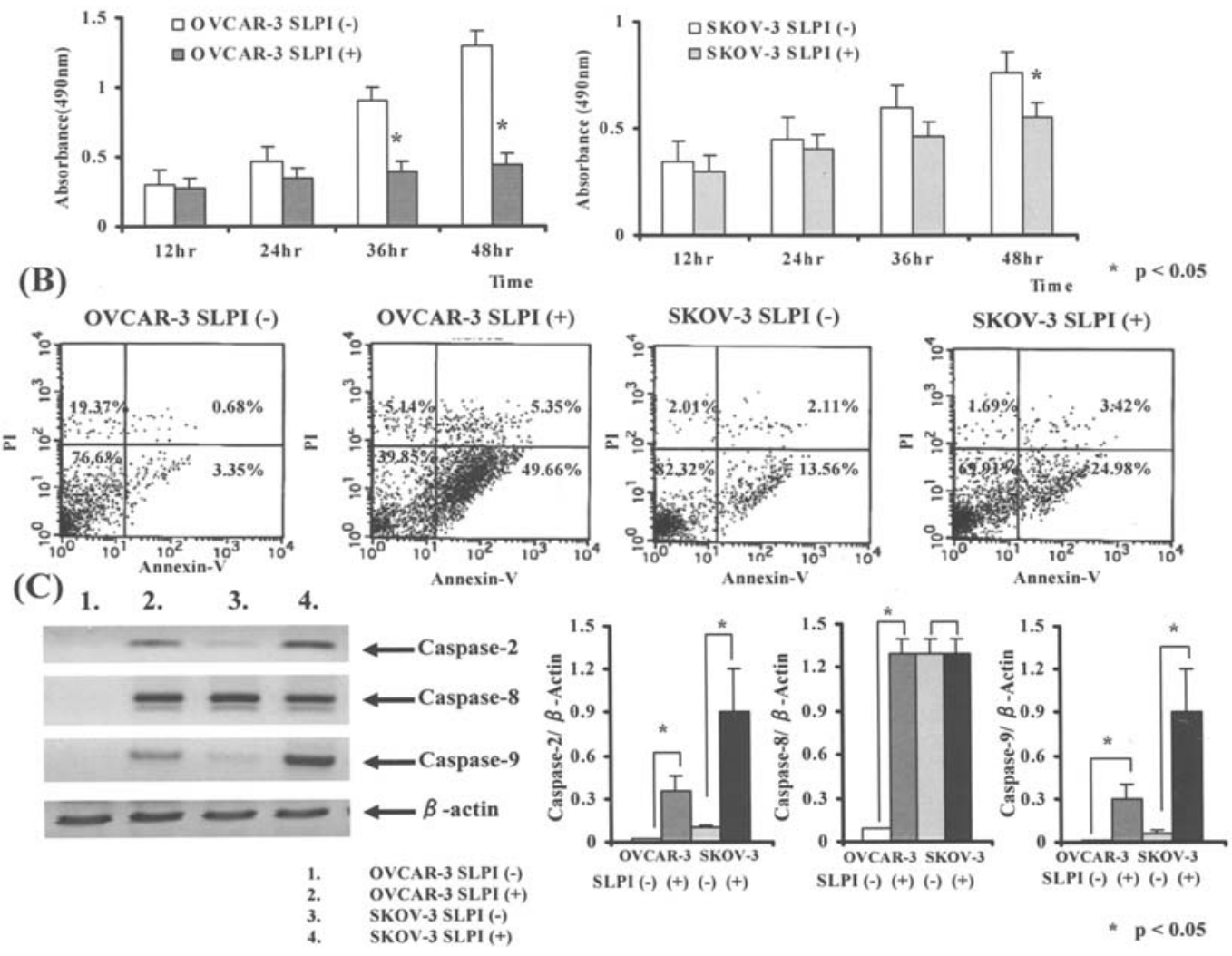

Figure 4. Effects on apoptosis by SLPI treatment into OVCAR-3 and SKOV-3 ovarian cancer cells. (A) Cell proliferation of MTS assay was analyzed transient transfection for 12, 24, 36 and $48 \mathrm{~h}$ into OVCAR-3 and SKOV-3 ovarian cancer cells. The absorbance was read at a wavelength of 490 nm using an ELISA plate-reader. The assays were carried out through quadruplate transfection experiments. (B) Representative flow cytometric data for apoptosis in OVCAR-3 and SKOV-3 by SLPI transient transfection treatment. (C) Total cell lysates were prepared from SLPI treatment in OVCAR-3 and SKOV-3 ovarian cancer cells; and then, cells were analyzed for Caspase-2, Caspase- 8 and Caspase- 9 expression by Western blotting. 3 -actin antibody was used as loading control in the same blot. The results represent the mean $\pm \mathrm{SD}$ of triplicate independent experiments $\left({ }^{*} \mathrm{p}<0.05\right)$. 
(A)

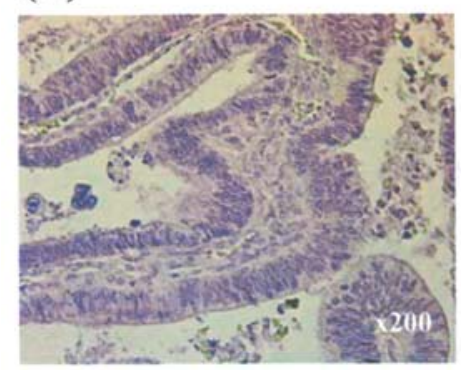

(B)

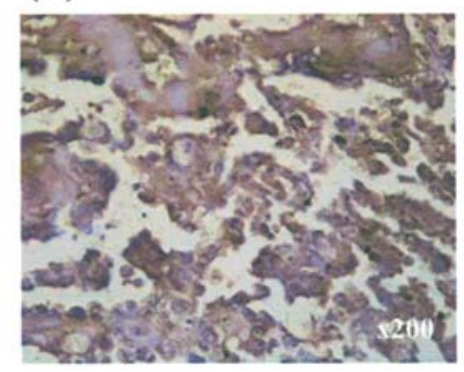

(C)

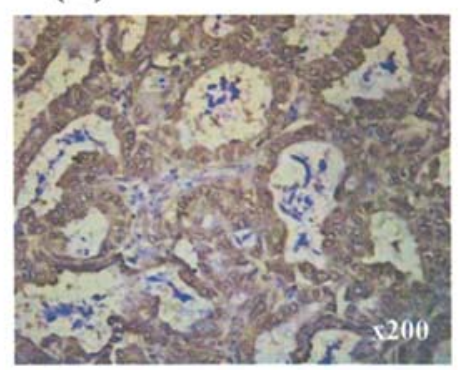

Figure 5. Representative immunostaining patterns of SLPI; (A) weak epithelial cell staining, (B) moderate epithelial staining, (C) strong epithelial cell staining (original magnification x200).

increased by SLPI on OVCAR-3. Expression of Caspase-2 and Caspase-9 were increased by SLPI on SKOV-3.

Inhibition of anchorage-independent cell growth in soft agar by transient transfected of SLPI into OVCAR-3 and SKOV-3 cell lines. Effects of SLPI expression on anchorageindependent cell growth in soft agar was analyzed using transient transfection of SLPI into OVCAR-3 and SKOV-3 cell lines. We found that the transient transfected with SLPI into OVCAR-3 and SKOV-3, and SLPI cells resulted in a significantly reduced number of colonies in the colony formation assay when compared to the control (Table II).

The biological parameters examined by immunostaining patterns of SLPI. Expression of SLPI was examined in human ovarian cancer patient tissues by immunostaining; Fig. 5 illustrates representative immunostaining patterns of SLPI. Weak epithelial staining was observed in 18 cases (31.0\%), moderate staining in 21 cases $(36.3 \%)$ and strong staining in 19 cases $(32.7 \%)$. Table III shows the distribution of cases scored as positive for each of the biological parameters examined, according to clinicopathological characteristics in the overall population (Mann-Whitney $U$ test, $\mathrm{p}<0.05$ ). However, SLPI expression was not correlated with prognostic factor for either disease-free or overall survival (data not shown).

\section{Discussion}

SLPI is an 11.7-kDa non-glycosylated, serine protease inhibitor that has a broad inhibitory spectrum against serine protease. However, it is unclear if overexpression of SLPI plays a role, therefore we examined whether SLPI expression correlated with clinico-pathological characteristics and investigated the mechanism by SLPI on ovarian cancer.

Previous studies showed SLPI was found to be significantly overexpressed in ovarian cancer samples compared with matched normal samples (22). Whereas, it is not clear how SLPI levels correlate with clinicopathological characteristics in patients. Our immunohistochemistry experiments with the ovarian tumor tissues reported here show SLPI expression was significantly correlated with low expression of SLPI and amount of ascites $(\mathrm{p}=0.021)$ and lymph node metastasis $(\mathrm{p}=0.011)$. And, SLPI show a decreased tendency with a correlation of SLPI expression with stage and histological type (Table III).
Table III. Association between SLPI and clinicopathological factors in ovarian cancer of the 58 patients.

\begin{tabular}{|c|c|c|c|}
\hline Variable & $\begin{array}{l}\text { No. of cases } \\
\quad(n=58)\end{array}$ & $\begin{array}{c}\text { SLPI } \\
(\text { mean } \pm \text { SE) }\end{array}$ & P-value \\
\hline Age (years) & & & 0.897 \\
\hline$\leq 60$ & 40 & $1.03 \pm 0.83$ & \\
\hline$>60$ & 18 & $1.00 \pm 0.77$ & \\
\hline Stage & & & 0.063 \\
\hline $\mathrm{I}+\mathrm{II}$ & 23 & $1.26 \pm 0.75$ & \\
\hline III+IV & 35 & $0.86 \pm 0.81$ & \\
\hline Grade & & & 0.645 \\
\hline $1+2$ & 24 & $0.96 \pm 0.81$ & \\
\hline $3 / \mathrm{NE}$ & 34 & $1.06 \pm 0.81$ & \\
\hline Histological type & & & 0.063 \\
\hline None serous & 23 & $1.26 \pm 0.75$ & \\
\hline Serous & 35 & $0.86 \pm 0.81$ & \\
\hline \multicolumn{4}{|l|}{ Amount of } \\
\hline ascites (ml) & & & $0.021^{\mathrm{a}}$ \\
\hline$<1000$ & 34 & $1.18 \pm 0.72$ & \\
\hline$\geq 1000$ & 24 & $0.68 \pm 0.89$ & \\
\hline \multicolumn{4}{|c|}{ Diameter of residual } \\
\hline tumor size $(\mathrm{cm})$ & & & 0.566 \\
\hline$\leq 2$ & 40 & $0.98 \pm 0.83$ & \\
\hline$>2$ & 18 & $1.11 \pm 0.76$ & \\
\hline \multicolumn{4}{|l|}{ Lymph node } \\
\hline metastasis $^{\mathrm{b}}$ & & & $0.011^{\mathrm{a}}$ \\
\hline Negative & 37 & $1.22 \pm 0.79$ & \\
\hline Positive & 21 & $0.67 \pm 0.73$ & \\
\hline
\end{tabular}

${ }^{a}$ Mann-Whitney $\mathrm{U}$ test. ${ }^{\mathrm{b}}$ Lymph node statue was assessed by CT imaging in 23 patients.

The potential therapeutic inhibitory effects mediated by TRAIL and TNF- $\alpha$ expression. TNF family is a potent cytokine which, on one hand, induces expression of inflammatory response proteins and, on the other, may induce apoptosis. 
These TRAIL and TNF- $\alpha$ death-signal pathway involves adaptor molecules activated by the interaction of ligand and receptors that recruit an initiator caspase into the apoptosissignaling complex. SLPI was initially identified as a macrophase-secreted protein that attenuates LPS-induced nitric oxide and TNF- $\alpha$ production in autocrine fashion $(23,24)$. In our study, transfected SLPI ovarian cancer cells induced the expression of TRAIL and TNF- $\alpha$. These results suggest that SLPI was able to exert anti-tumor effects through TRAIL-DR4 and DR-5, and TNF- $\alpha$-TNFR-I interaction against this malignancy.

Cells usually respond to genotoxic stress by activating cell cycle checkpoints, and by blocking further progression into the cell cycle, thus allowing the cells to repair damage. In this study, cell cycle arrest was mainly observed at subG ${ }_{1}$ phase by transfected cells with SLPI as compared to control. These data indicate that SLPI might act to cause cell cycle arrest at the subG $\mathrm{G}_{1}$ phase, supporting the idea that SLPI is inhibitory to cell growth and a significant proportion of cells were found to be apoptotic. Several previous reports also showed that SLPI acts during apoptosis $(10,25)$. SLPI induced apoptosis on both OVCAR-3 and SKOV-3 cancer cells, as shown in Fig. 4A and B. To trace the steps in the apoptotic cascade, we evaluated the activation of the initiator caspases, Caspase-2, Caspase- 8 and Caspase-9. We showed that these capsases are significantly activated. Overall, SLPI shows potential therapeutic inhibitory effects mediated by TRAIL and TNF- $\alpha$ expression that could induce apoptosis by interaction with DR-4, DR-5, TNFR-I through Caspase-2, Caspase- 8 and Caspase- 9 .

In summary, our studies have revealed a critical role for SLPI in the functional activity and effects on ovarian cancer cells. SLPI may provide a possible therapeutic target for the treatment of ovarian cancer.

\section{Acknowledgements}

We are grateful to Dr T. Nukiwa for providing the SLPI proteins to the Department of Respiratory Oncology and Molecular Medicine, Institute of Development, Aging and Cancer, Tohoku University, Aobaku Sendai, Japan for providing us with a full-length SLPI cDNA construct encoding SLPI proteins. This study was supported in part by grants-inaid for Science Research grant from the Japan Society for the Promotion of Science (17791119; K.N.) and The Kawasaki Foundation for Medical Science and Medical Welfare (K.N.).

\section{References}

1. Abe T, Kobayashi N, Yoshimura K, Trapnell BC, Kim H, Hubbard RC, Brewer MT, Thompson RC and Crystal RG: Expression of the secretory leukoprotease inhibitor gene in epithelial cells. J Clin Invest 87: 2207-2215, 1991.

2. Franken C, Meijer CJ and Dijkman JH: Tissue distribution of antileukoprotease and lysozyme in humans. J Histochem Cytochem 37: 493-498, 1989.

3. Jin FY, Nathan C, Radzioch D and Ding A: Secretory leukocyte protease inhibitor: a macrophase product induced by and antagonistic to bacterial lipopolysaccharide. Cell 88: 417-426, 1997.

4. Boudier C, Cadene M and Bieth JG: Inhibition of neutrophil cathepsin $\mathrm{G}$ by oxidized mucus protease inhibitor. Effect of heparin. Biochemistry 38: 8451-8457, 1999.
5. Hiemstra PS, Maassen RJ, Stolk J, Heinzel-Wieland R, Steffens GJ and Dijkman JH: Antibacterial activity of antileukoprotease. Infect Immun 64: 4520-4524, 1996.

6. Shine N, Konopka K and Duzgunes N: The anti-HIV-1 activity associated with saliva. J Dent Res 76: 634-640, 1997.

7. Lentsch AB, Jordan JA, Czermak BJ, Diehl KM, Younkin EM, Sarma V and Ward PA: Inhibition of NF-kappaB activation and augmentation of Ikappa B beta by secretory leukocyte protease inhibitor during lung inflammation. Am J Pathol 154: 239-247, 1999 .

8. Ward PA and Lentsch AB: Endogenous regulation of the acute inflammatory response. Mol Cell Biochem 234-235: 225-228, 2002.

9. Ashcroft GS, Lei K, Jin W, Longenecker G, Kulkarni AB, Greenwell-Wild T, Hale-Donze H, McGrady G, Song XY and Wahl SM: Secretory leukocyte protease inhibitor mediates nonredundant functions necessary for normal wound healing. Nat Med 6: 1147-1153, 2000.

10. Maemondo M, Saijo Y, Narumi K, Kikuchi T, Usui K, Tazawa R, Matsumoto K, Nakamura T, Sasaki K, Takahashi M, Niitsu Y and Nukiwa T: Gene therapy with secretory leukoprotease inhibitor promoter-controlled replication-competent adenovirus for non-small cell lung cancer. Cancer Res 64: 4611-4620, 2004.

11. Rein DT, Breidenbach M, Kirby TO, Han T, Siegal GP, Bauerschmitz GJ, Wang M, Nettelbeck DM, Tsuruta Y, Yamamoto M, Dall P, Hemminki A and Curiel DT: A fibermodified, secretory leukoprotease inhibitor promoter-based conditionally replicating adenovirus for treatment of ovarian cancer. Clin Cancer Res 11: 1327-1335, 2005.

12. Nagata S: Apoptosis by death factor. Cell 88: 355-365, 1997.

13. Lincz LF: Deciphering the apoptotic pathway: all roads lead to death. Immunol Cell Biol 76: 1-19, 1998.

14. Griffith TS, Lynch DH and TRAIL: a molecule with multiple receptors and control mechanisms. Curr Opin Immunol 10: 559-563, 1998.

15. Le Blanc HN and Ashkenazi A: Apo2L/TRAIL and its death and decoy receptors. Cell Death Differ 10: 66-75, 2003.

16. Wajant H, Gerspach J and Pfizenmaier K: Tumor therapeutics by design: targeting and activation of death receptors. Cytokine Growth Factor Rev 16: 55-76, 2005.

17. Kelley RF, Totpal K, Lindstrom SH, Mathieu M, Billeci K, Deforge L, Pai R, Hymowitz SG and Ashkenazi A: Receptor selective mutants of apoptosis-inducing ligand 2/tumor necrosis factor-related apoptosis-inducing ligand reveal a greater contribution of death receptor (DR) 5 than DR4 to apoptosis signaling. J Biol Chem 280: 2205-2212, 2005.

18. King AE, Fleming DC, Critchley HO and Kelly RW: Regulation of natural antibiotic expression by inflammatory mediators and mimics of infection in human endometrial epithelial cells. Mol Hum Reprod 8: 341-349, 2002.

19. Stylianou E, Yndestad A, Sikkeland LI, Bjerkeli V, Damås JK, Haug T, Eiken HG, Aukrust P and Frøland SS: Effects of interferon-alpha on gene expression of chemokines and members of the tumour necrosis factor superfamily in HIV-infected patients. Clin Exp Immunol 130: 279-285, 2002.

20. Ibrahim SM, Ringel J, Schmidt C, Ringel B, Müller P, Koczan D, Thiesen HJ and Löhr M: Pancreatic adenocarcinoma cell lines show variable susceptibility to TRAIL-mediated cell death. Pancreas 23: 72-79, 2001

21. Burvall K, Palmberg L and Larsson K: Expression of TNF alpha and its receptors R1 and R2 in human alveolar epithelial cells exposed to organic dust and the effects of 8-bromo-cAMP and protein kinase A modulation. Inflamm Res 54: 281-288, 2005.

22. Tsukishiro S, Suzumori N, Nishikawa H, Arakawa A and Suzumori K: Use of serum secretory leukocyte protease inhibitor levels in patients to improve specificity of ovarian cancer diagnosis. Gynecol Oncol 96: 516-519, 2005.

23. Jin F, Nathan CF, Radzioch D and Ding A: Lipopolysacchariderelated stimuli induce expression of the secretory leukocyte protease inhibitor, a macrophase-derived lipopolysaccharide inhibitor. Infect Immun 66: 2447-2452, 1998.

24. Henriksen PA, Hitt M, Xing Z, Wang J, Haslett C, Riemersma RA, Webb DJ, Kotelevtsev YV and Sallenave JM: Adenoviral gene delivery of elafin and secretory leukocyte protease inhibitor attenuates NF-кB-dependent inflammatory responses of human endothelial cells and macrophases to atherogenic stimuli. J Immunol 172: 4535-4544, 2004.

25. Odaka C, Mizuochi T, Yang J and Ding A: Murine macrophages producesecretory leukocyte protease inhibitor during clearance of apoptotic cells: implications for resolution of the inflammatory response. J Immunol 171: 1507-1514, 2003. 